\title{
The North Atlantic Coast Comprehensive Study and the US Army Corps of Engineers Sandy Recovery Program
}

\author{
Roselle Henn ${ }^{1, a}$, Joseph Vietri ${ }^{1}$, and David Leach ${ }^{2}$ \\ ${ }^{1}$ Coastal Storm Risk Management - National Planning Center, US Army Corps of Engineers, 301 General Lee Avenue, Brooklyn, New \\ York, 11252, USA \\ ${ }^{2}$ North Atlantic Division, US Army Corps of Engineers, 301 General Lee Avenue, Brooklyn, New York, 11252, USA
}

\begin{abstract}
The Disaster Relief Appropriation Act of 2013 (P.L. 113-2) recognized the need to comprehensively evaluate the existing and planned measures to reduce the flooding risk from tidally-influenced storm surges as well as other alternatives for areas at risk to future storm damages. The legislation directed the US Army Corps of Engineers to undertake a Comprehensive Study of the Sandy impacted areas in the North Atlantic Division (Maine to Virginia). This paper reviews the findings and outcomes of the NACCS and their application across the USACE's Sandy Recovery Program.
\end{abstract}

\section{Introduction}

On January 29, 2013, the Disaster Relief Appropriations Act, 2013, Public Law 113-2 [1], was enacted to assist in the recovery in the aftermath of the hybrid cyclone-nor'easter known as Hurricane Sandy. The Act directed the Secretary of the Army to "...conduct a comprehensive study to address the flood risks of vulnerable coastal populations in areas that were affected by Hurricane Sandy within the boundaries of the North Atlantic Division of the Corps of Engineers..." (the region extending from Maine to Virginia). The study area included the 10 northeast States and the District of Columbia and focused on locations that were greatly impacted by Hurricane Sandy. In responding to the legislated mandate, the purpose of the "North Atlantic Coast Comprehensive Study: Resilient Adaptation to Increasing Risk" [2] (NACCS) was to develop strategies accessible to all stakeholders that would facilitate preparations for future storms, climate change, and sea level change. This paper summarizes the findings and outcomes of the study and discusses how they are being implemented in the Sandy Recovery Program.

\section{Background}

\subsection{Hurricane Sandy}

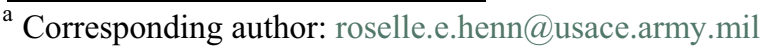

Hurricane Sandy was an extraordinary storm, resulting in significant damages in the coastal areas extending from Cape May, New Jersey to Montauk Point, New York and concentrated in the New York-New Jersey Harbor. Peak water levels indicate that Hurricane Sandy was at least greater than a 200 year event, greatly exceeding project design levels. This resulted in damages throughout the New York City metropolitan area. Beyond the New York Bight, including New Jersey, along the north shore of Long Island, NY, Connecticut, Rhode Island, southern Massachusetts, and the Atlantic coasts of Delaware and Maryland, storm tides, although still significant, were considerably lower, typically a 20 to 30 year event. Farther away, in Massachusetts north of Cape Cod, New Hampshire, and Maine to the north and the Chesapeake Bay coastline of Maryland and Virginia to the south, Hurricane Sandy was less than a 10 year event [3].

The Congressional response to the devastation in the wake of Hurricane Sandy represented an effort to address the needs of the regional system and vulnerable populations at risk in coastal regions in the U.S. Army Corps of Engineers (USACE) North Atlantic Division. The series of high magnitude, devastating storm events (Hurricanes Katrina and Rita in 2005, Hurricane Irene in 2011, and Hurricane Sandy in 2012), as well as the trend toward sea level change as a probable future condition, comprehensively evaluate the existing and planned measures to reduce the flooding risk from tidally influenced storm surges as well as other alternatives for areas at risk to future storm damages. 


\subsection{Foundation of the NACCS}

The Comprehensive Study is based on the "Infrastructure Systems Rebuilding Principles" advanced by the National Oceanic and Atmospheric Administration (NOAA) and the USACE [4]. The purpose of the Rebuilding Principles were to improve long-term performance of coastal rebuilding and restoration actions undertaken through the Infrastructure Systems Recovery Support Functions under the National Disaster Recovery Framework following Hurricane Sandy by implementing Executive Order 11988 and these consistent principles on a regional scale that anticipate a changing environment; integrate economic, social, and environmental resiliency and sustainability; and promote long term community protection. The three Principles are: 1) Work together in a collaborative manner across multiple scales of governance (i.e., local, State, Tribal, and Federal) and with relevant entities outside the government to develop long-term strategies that promote public safety, protect and restore natural resources and functions of the coast, and enhance coastal resilience; 2) Improve coastal resilience by pursuing a systems approach that incorporates natural, social, and built systems as a whole; and 3) Promote increased recognition and awareness of risks and consequences among decision makers, stakeholders, and the public. These Principles built on lessons learned from Hurricanes Katrina and other major storm events, including Sandy.

The Hurricane Sandy Performance Evaluation Study [6], another requirement of the Sandy legislation, provided specific recommendations which were also foundational to NACCS. The report assessed the performance of constructed coastal storm risk reduction projects during Sandy to determine if they had reduced damages as intended. The Evaluation Study concluded that delivery of more comprehensive protection to affected coastal areas would require a broader approach to the investigation and planning of flood and coastal storm damage reduction projects that includes consideration of potential flooding of back-bay reaches of barrier islands among other concerns. It also found that can communities differ in their valuation of coastal environments and that reconciling those differences can be challenging. The Evaluation Study recommended that the efficacy of natural and engineered dunes in reducing risks of coastal storm damages be evaluated. Finally, the report recommended that a broader range of project benefits, including resilience and recovery, be considered to more accurately evaluate the impacts of extreme storm events.

The NACCS Study area was defined by the very high and high impact areas. Following Sandy, Federal, State, and local government agencies and NGOs initiated a major response and recovery effort to repair, replace, and restore homes, industry, and critical infrastructure under the National Disaster Recovery Framework. This effort, which culminated in the Hurricane Sandy Rebuilding Strategy [6], has changed the physical and cultural landscape of the impacted areas and has heightened social and political awareness of the potential impacts from future storms.

To more clearly articulate the universe of measures and how USACE would use them to manage coastal storm risk, the USACE published "Coastal Risk Reduction and Resilience: Using the Full Array of Measures" [7]. This report introduced the term "Natural and Nature-Based Features" (NNBF) to refer to the universe of natural features, created and evolving over time through the actions of physical, biological, geologic, and chemical processes operating in nature (Figure 1). Nature-based features are those that may mimic characteristics of natural features but are created by human design, engineering, and construction to provide specific services such as coastal risk reduction. Scientific research to better understand the role of natural landscapes nature-based features and natural processes in the context of coastal and fluvial flood risk has and continues to be undertaken internationally [8-11]. The USACE paper advocated an integrated approach to risk reduction through the incorporation of natural and nature-based features in addition to nonstructural and structural measures that also improve social, economic, and ecosystem resilience.

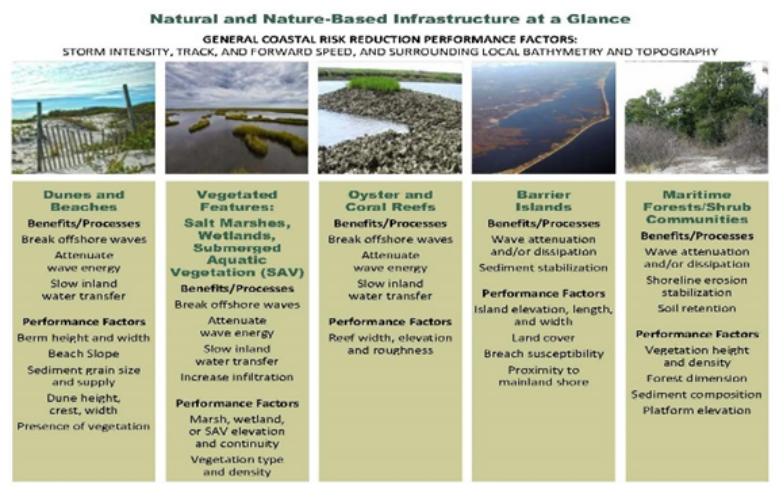

Figure 1. Natural and Nature-Based Features

\section{The North Atlantic Coast Comprehensive Study}

The goals of the Comprehensive Study were to (1) provide risk reduction strategies to subjected vulnerable coastal populations, and (2) promote coastal resilient communities to ensure a sustainable and robust coastal landscape system, considering future sea level rise and climate change scenarios, to reduce risk to vulnerable population, property, ecosystems, and infrastructure. The 
Comprehensive Study included a Coastal Storm Risk Management Framework as well as storm suite modeling, coastal GIS analysis, and related evaluations, for the affected coastlines. The Study identified existing green/nature-based infrastructure, include an evaluation of the performance of green/nature-based infrastructure during Hurricane Sandy and other recent storms, and consider the performance of green/nature-based infrastructure in reducing the impacts of coastal storm flooding, as well as other impacts at a larger scale and as a system. Led by the USACE Coastal Storm Damage Reduction Planning Center of Expertise, the Team was comprised of coastal planners, engineers, and scientists from across the USACE enterprise.

In the aftermath of Sandy, the Federal Emergency Management Agency (FEMA) Modeling Task Force (MOTF) developed a Total Damage (Composite Surge / Precipitation / Wind Map) County Impact Analysis to define the area impacted by Hurricane Sandy and document the economic impacts related to storm surge, intense rainfall, and high winds. The areas of greatest impacts were in New York and New Jersey. The Study Area Map (Figure 2) provides a color-coded overview of the damages using the following criteria:

- Very High (Purple): County population greater than 10,000 exposed to surge.

- High (Red): County population of 500 to 10,000 exposed to surge, or modeled wind damages greater than $\$ 100 \mathrm{M}$, or precipitation greater than 8 inches.

- Moderate (Yellow): County population of 100 to 500 exposed to surge, or modeled wind damages of $\$ 10$ to $\$ 100 \mathrm{M}$, or precipitation of 4 to 8 inches.

- Low (Green): No storm surge impacts, or modeled wind damages less than $\$ 10 \mathrm{M}$, or precipitation less than 4 inches.

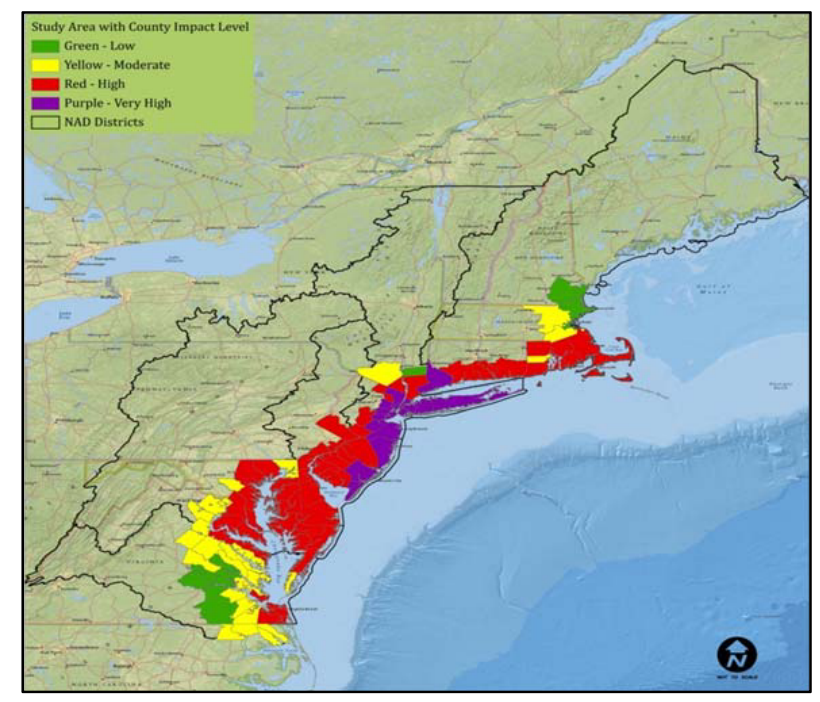

Figure 2: NACCS Study Area
The study was to evaluate flood risks and identify areas warranting additional analysis, as well as the institutional and other barriers to providing protection. The final report for the NACCS Study (NACCS) was submitted by the Assistant Secretary of the Army for Civil Works to the US Congress on 28 January 2015.

Rising sea levels and climate change are expected to have a profound effect on the coastal region in the study area. Impacts will likely include shoreline retreat from erosion and inundation, increased frequency and magnitude of storm-related flooding, temperature changes, and saltwater intrusion into the estuaries and aquifers. Relative sea level rise will not only inundate larger coastal areas, but will also be a driver of change in habitat and species distribution, as will other effects of climate changes such as increased sea surface temperatures. Additionally, the presence of developed shorelines behind many of these habitats will prevent natural barrier island overwash and migration landward in response to relative sea level rise. Habitat changes may be structural or functional; species that depend on coastal habitats for feeding, nesting, spawning, protection, and other activities could be severely impacted if this critical habitat is converted or lost. Additional services provided by coastal habitats would also be affected.

The NACCS addresses sea level change in accordance with an internal guidance document on Sea Level Change with applicable to all coastlines within the United States[12]. In the case of the NACCS, relative sea levels are rising throughout the entire study area. USACE guidance specifies a method for developing relative sea level change (RSLC) scenarios to be used in developing the range of plausible future conditions in the planning process. In addition, NOAA recently recommended its own set of sea level change scenarios in a report entitled Global Sea Level Rise Scenarios for the US National Climate Assessment [13]. The NACCS considered scenarios from both documents. USACE guidance also specifies a risk-based framework for evaluation of RSLC impacts to projects in the presence of other forces (in this case erosion, storm surge, riverine flooding events, etc.).

\subsection{NACCS Findings and Outcomes}

The Comprehensive Study identified and evaluated coastal risks and conditions of ten states, from New Hampshire to Virginia, and the District of Columbia. Across this region, and in many other coastal settings, communities face tough choices as they prepare for changing conditions, including potentially devastating coastal storms. A central NACCS finding is that a more comprehensive protection can only be realized when individuals and government agencies at non-federal and 
Federal levels collectively recognize, understand, and act to manage and effectively reduce risks attributed to threats posed by flooding and coastal storms. Managing coastal storm risk as a shared responsibility by all levels of government and individual property owners, requires that diverse perspectives be addressed and balanced. Adapting to risk and considering combinations of solutions across agencies and partners is key to being ready for the next big storm.

Another major finding is that risk management and resilience are enhanced when the full array of coastal storm risk management measures are evaluated as part of an integrated plan. Figure 3 illustrates the measures discussed in the NACCS which include:

- $\quad$ Structural and NNBF

- Non-structural

- Policy and programmatic elements, and

- Blended solutions... which are particularly key for resilience and adaptation planning over time.

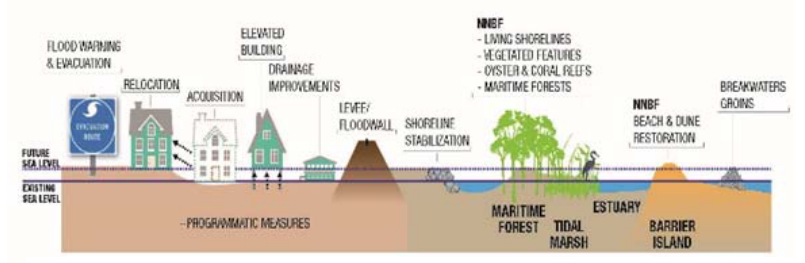

Figure 3. The Full Array of Coastal Storm Risk Management Measures

\subsection{The Coastal Storm Risk Management Framework}

One of the major outcomes of the NACCS is the the Coastal Storm Risk Management Framework (Figure 4). Framework looks at vulnerability across the Study reaches and identifies measures that could be used to manage risk. The Study does not make specific project recommendations, but illustrates a systems approach and how it can be applied through using the Framework. The Framework was developed to provide regional partners with a methodology that they can adjust to meet their needs/values within their specific communities. The NACCS Framework offers a common science-based decision framework for the integration of coastal investments and wise coastal zone planning. It is scalable/customizable for any coastal watershed. Managing coastal flood risk is complex. There are economic, social, and environmental factors to consider, layers of governments involved, and dozens of ways to reduce risk, from using manmade features like levees and seawalls to using natural features like salt marshes and maritime forests. Because every location is different, there is no one fixed solution set. Having a methodology that public and private interests can follow together to assess risk and identify solutions is offered as a primary tool in achieving the integration of all levels of

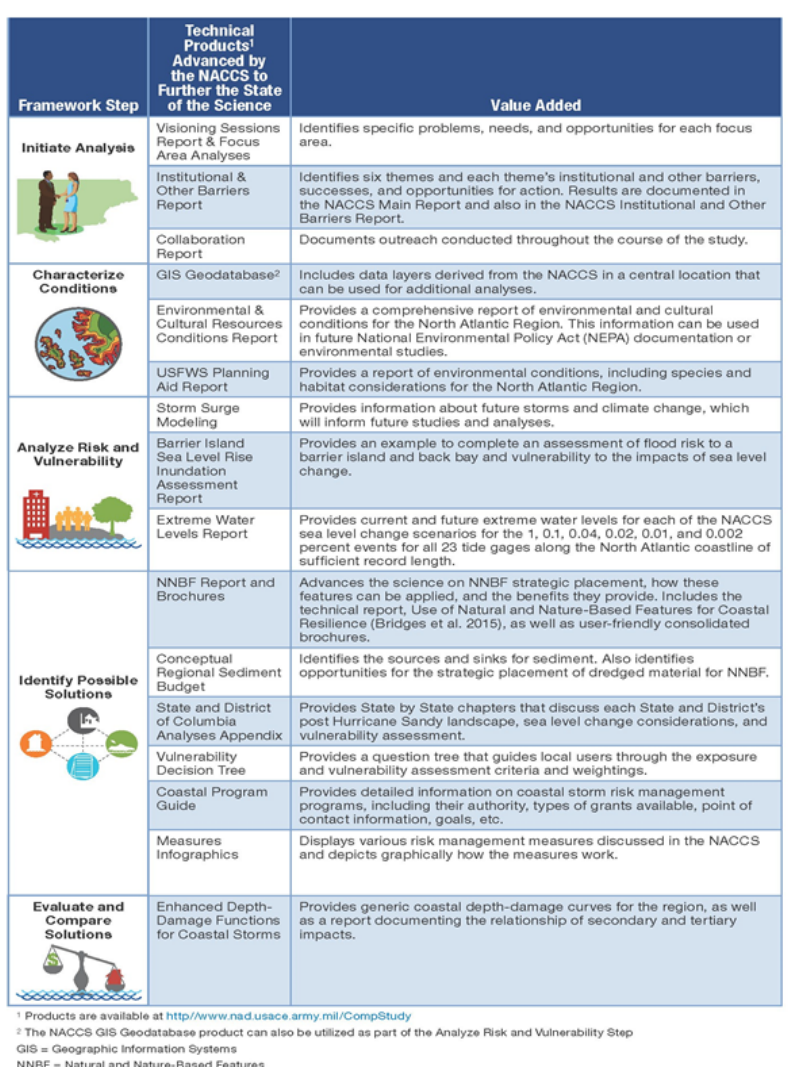

Figure 4. The Coastal Storm Risk Management Framework

The Coastal Storm Risk Management Framework includes evaluations of strategies in response to increased risk from coastal storms and sea level rise. Subsequent analyses at a community specific scale can be undertaken to incorporate climate change adaptation and projected future vulnerabilities.

Complex interactions between alluvial and tidally influenced tributaries will change. The combination of extreme water levels and sea level change (some areas of the NACCS study area will likely experience variations in the effects of sea level change due to relative effects of land and tidal processes) will vary across the study area. Furthermore, the coastal landscape responses will vary across the study area because of the myriad of geomorphological and land use characteristics. Flood frequency, erosion and sedimentation, and environmental responses will depend on site and regional characteristics. Thus, subsequent analyses at a community-specific scale must consider the various components of long-term climate change adaptation and the various strategies and corresponding measures for projected vulnerabilities. This approach will allow 
communities to consider the appropriate short-term response to address existing levels of exposure and vulnerability and avoid the need to reinvest in a different solution based on the rate of sea level change over time.

Supporting the Framework are other technical products and tools including storm suite modeling, coastal GIS analysis, and economic depth-damage elated evaluations, for the affected coastlines. The Framework and tools stemming from the Comprehensive Study are portable and can be adapted for use in other coastal regions.

\section{The USACE Sandy Recovery Program}

The USACE Sandy Recovery Program has made significant progress in restoring the coastal risk reduction projects that were damaged by Sandy. The Flood Control and Coastal Emergencies (FCCE) program has restored 25 projects that were constructed at the time of the Sandy and performed as designed. Restoration to their initial design templates was needed as considerable beach nourishment material was lost during the storm causing significant shoaling in the region's navigation system. The Sandy Recovery Program has also restored 86 channels providing safe navigation to deep-water ports, intra-coastal waterways, and harbors throughout the northeastern states.

At the time that Sandy occurred there were 19 projects that were authorized for construction, but which, for a variety of reasons, had not been fully completed. The largest and most complex of these, Fire Island to Montauk Point, NY (83 miles of coastal Long Island) and Rockaway-Jamaica Bay, NY (in New York City) are being reformulated using the findings and outcomes of the NACCS, as are the 16 studies that were underway when Sandy made landfall.

The NACCS identified 9 highly vulnerable coastal areas, termed Focus Areas, that warranted additional research as they had neither projects or studies underway when Sandy occurred. Shown on Figure 5, the Focus Areas fall into two groups: large urban centers (New York-New Jersey Harbor and Tributaries, New York and New Jersey; City of Baltimore, Maryland; Metropolitan Washington, District of Columbia;, and City of Norfolk Virginia) and embayment areas west of the Atlantic coast (Coastal Rhode Island; Coastal Connecticut; Nassau County Back Bays, New York; New Jersey Back Bays, New Jersey; and Delaware Inland Bays and Delaware Bay Coast, Delaware). As of May 2016, studies have been initiated for City of Norfolk and New Jersey Back Bays and initial planning steps are being taken to develop comprehensive, resilient strategies for these vulnerable locations.

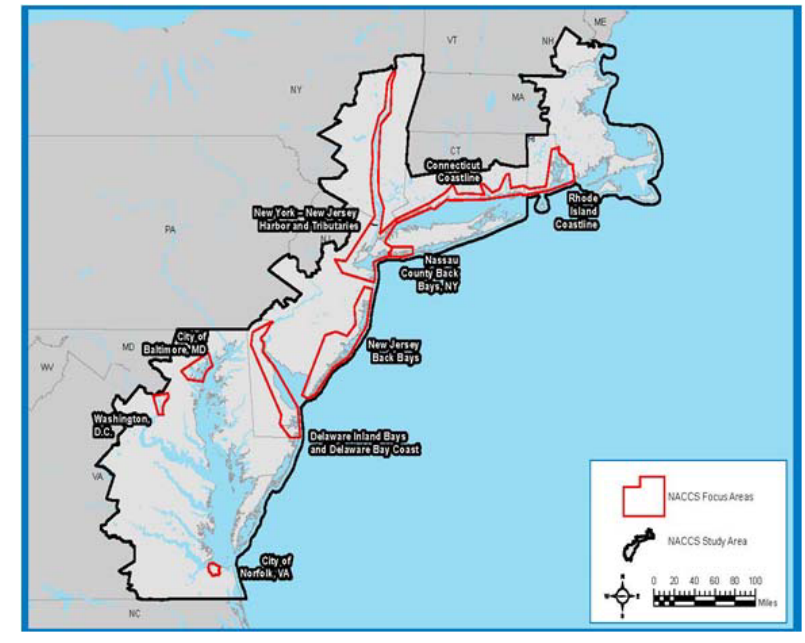

Figure 5. The North Atlantic Coast Focus Areas

\section{References}

1. United States Government (2013). Disaster Relief Appropriations Act, 2013. United States Government Printing Office. http://www.gpo.gov/fdsys/pkg/PLAW113publ2/html/PLAW-113publ2.htm

2. US Army Corps of Engineers (2015). North Atlantic Coast Comprehensive Study: Resilient Adaptation to Increasing Risk. U.S. Army Corps of Engineers. Washington DC

http://www.nad.usace.army.mil/CompStudy

3. Federal Emergency Management Agency (2013). Hurricane Sandy in New Jersey and New York Building Performance Observations, Recommendations, and Technical Guidance. Mitigation Assessment Team Report. FEMA P-942

4. National Oceanic and Atmospheric Administration and the U.S. Army Corps of Engineers (2013). Infrastructure Systems Rebuilding Principles, February. https://coast.noaa.gov/digitalcoast/publications/rebu ilding-principles

5. US Army Corps of Engineers (2013). Hurricane Sandy Coastal Projects Performance Evaluation Study. Washington, D.C.

http://www.nan.usace.army.mil/Portals/37/docs/civil works/SandyFiles/USACE_Post-

Sandy_Coastal_Projects_Performance_Evaluation_ Study.p. $d f$

6. Hurricane Sandy Rebuilding Task Force (2013). Hurricane Sandy Rebuilding Strategy - Stronger Communities, A Resilient Region. Washington DC.

7. US Army Corps of Engineers (2013). Coastal Risk 
Reduction and Resilience: Using the Full Array of Measures. CWTS 2013-3. Washington, DC:

Directorate of Civil Works, U.S. Army Corps of Engineers.

http://www.corpsclimate.us/docs/USACE_Coastal_R isk_Reduction_final_CWTS_2013-3.pdf

8. The Parliamentary Office of Science and Technology (20110. Natural Flood Management. Postnote Number 396 Millbank, London SWIP 3JA T02072192840E post@parliament.uk www.parliament.uk/post.

9. Environment Agency (2014). Working with Natural Processes to Reduce Flood Risk R\&D Framework: Science Report. SC130004/R2 Horizon House,

Deanery Road, Bristol, BS1 9AH www.environmentagency.gov.uk

10. Day, J.W. Jr., Rismondo, A., Scarton, F., Are, D., and Cecconi, G. (1998). Relative Sea Level Rise and Venice Lagoon Wetlands. Journal of Coastal Conservation 4:27-34. EUCC Opulus Press Upssala, Sweden.

11. Bas W. Borsjea, Bregje K. van Wesenbeeck, Frank Dekker, Peter Paalvast, Tjeerd J. Bouma, Marieke M. van Katwijkf, and Mindert B. de Vries (2011). How ecological engineering can serve in coastal protection. Ecological Engineering 37 (2011) 113122.

12. USACE (2013). Incorporating Sea Level Change in Civil Works Programs. Engineer Regulation 1100-2- 8162. U.S. Army Corps of Engineers.

13. US Army Corps of Engineers (2011). Sea-Level Change Considerations for Civil Works Programs. USACE Circular No. 1165-2-211. Washington, DC.

14. NOAA (2012). Global Sea Level Rise Scenarios for the US National Climate Assessment. NOAA Tech Memo OAR CPO-1. Silver Spring, MD: Climate Program Office. 